\title{
Desclassification in knowledge organization: a post-epistemological essay
}

\author{
Desclassificação na organização do conhecimento: \\ ensaio pós-epistemológico
}

Antonio GARCÍA GUTIÉRREZ

\begin{abstract}
The contents of the digital network stem from different forms, logics and cultures of knowledge. Once on the Net, however, they are all submitted to unifying formats and logics provided by digital technology itself. A technology is, first of all, the product of a given culture. Every culture and identity classifies and names all kinds of material and symbolic objects. Nowadays, the West is the one culture that has taken upon itself the task of global classification supported by its own digital networks. Classification is an epistemological tool provided by modern rationality whose internal structures and modes of inference are derived from metonymic, dichotomic and analogical reductions of the diversity of current worlds. In this paper, a kind of practical Hermeneutics, called "declassification", is introduced and proposed as the route to a knowledge which overcomes organizational epistemology. Declassification is an open system that installs logical pluralism in the core of understanding and enunciation processes through meta-cognitive tools.
\end{abstract}

Keywords: Classification. Digital network. Epistemology. Hermeneutics.

\section{Resumo}

O conteúdo da rede digital origina-se a partir de diferentes formas, lógicas e culturas de conhecimento. Uma vez na Net, no entanto, eles são todos submetidos para se unificarem formatos e lógicas fornecidos pela própria tecnologia digital. Uma tecnologia é, em primeiro lugar, o produto de uma cultura fornecida. Toda cultura e identidade classificam e nomeiam todo tipo de material e objetos simbólicos. Nos dias de hoje, o Oeste é a cultura que tomou para si a tarefa da classificação global suportada por suas próprias redes digitais. Classificação é uma ferramenta epistemológica fornecida pela racionalidade moderna, cujas estruturas internas e modos de inferência são derivadas das reduções metonímicas, dicotonímicas e analógicas da diversidade dos mundos atuais. Neste papel, um tipo de hermenêutica prática, chamada "desclassificação", é introduzida e proposta como um caminho para um conhecimento que supera a epistemologia organizacional. Desclassificação é um sistema aberto que instala pluralismo lógico no núcleo do entendimento e processos de enunciação, através de ferramentas metacognitivas.

Palavras-chave: Classificação. Rede digital. Epistemologia. Hermenêutica.

\section{Introduction}

This article sets out to review the dominant epistemological position of Knowledge Organization (KO) and to propose an alternative perspective of thought - complementary rather than substitutive - from which we may consider KO differently, through other paths, towards different sensibilities, relocating the epistemic place from which $\mathrm{KO}$ theories and practices are often enunciated.

\footnotetext{
1 Professor, Universidad de Seville, Faculdade de Communicación. R. Américo Vespúcio, s/n., 41092, Servilla, España. E-mail: <algarcia@us.es>. Recebido em 16/2/2011 e aceito para publicação em 28/3/2011.
} 
Our field of study requires an "epistemological turn" in order to address the increasing challenges of an ever-changing, convulsive and heterogeneous world. But that "turn" should be so complex that the conception of Epistemology itself could be overcome. Perhaps there is little to lose by making an attempt, when taking into account, like the Portuguese social researcher Santos (1989), that Epistemology imposes requirements on scientific disciplines that it is incapable of imposing on itself, for which reason its reliability should be kept under surveillance.

Addressing the core problems of $\mathrm{KO}$ should not only be attempted by authors, schools, tendencies or languages of this knowledge area, since the issues to be addressed surpass positivist demarcations, delocalize themselves, and then reappear with a different aspect both transgressive and truly renovating - in the eyes of transdisciplinarity.

It is therefore necessary to start from an open study focusing attention on the scientific object itself, although from the perspective of other alliances and breakups. More specifically, the postcolonial theories (Bhabha, 1994; Mignolo, 2003), feminist positions (Olson, 2003), polyvalent (Peña, 1992) and paraconsistent (Costa, 1997) logics, rational sensitivity or aesthesia (Sodré, 2006), imperfect rationality (Elster, 1989), diatopical hermeneutics (Santos, 2005) and complex thought (Morin, 1996), among other critical approaches, would have to open a dialogue that promotes the in-depth revision of the conceptions, procedures, relationships and actions revolving around $\mathrm{KO}$.

Already installed in psychism, classification - an epistemological operation of a general nature - doubly affects the work of KO practitioners due to the fact that one of its essential routines is precisely a specific type of classification. The act of classifying is not only governed by a set of explicit organizational rules, but also cognitive, unconscious and automatic behavioural patterns linked to ideology, culture, identity and memory which confine pluralism and interpretation.

In the final sections of this paper, a different and post-epistemological position of enunciation is proposed for the problems and issues arising from $\mathrm{KO}$ in an increasingly globalized world of growing cultural homogenization, in addition to two specific operators of $\mathrm{KO}^{(2)}$ applicable to the management of historic, media, social and cultural discourses, with the aim of illustrating the potential of declassifying thought.

\section{Classification as an epistemological and technical operation}

Classification is a first-order gnoseological and epistemological operation that impregnates totality, and totally our relationship with the world. The mind perceives all kinds of objects - material or symbolic - according to categories provided by a given culture - a scientific paradigm, in this case - in a way that the representations of such objects are just re-semantizations elaborated in complex processes of semiosis that habitually transcends cultures. This should not pose any problem, since all cultures and identities hyper-classify the world as part of their "language-games", if it were not for the fact that, as Rorty (1983) stated, Epistemology is a mere episode of Western culture, and the West - in the cultural sense - is the most powerful driving force ever known, not only behind the classification and re-classification of the present, but also of our own past and future and those of others. This resignification has been reinforced and accelerated thanks to digital technology.

The digital network, together with incessant and routine classifying operations promoted by Western culture, acts upon an open space in which other civilizations and cultures - also important producers of knowledge and memories - become more vulnerable. "Digitality" already imposes a certain logical order on the world, because, as with any other technology, it is primarily a "technologic", an instrument with a symbolic reach that imperceptibly transfers the codes of the culture that designed it. In this way, there are simultaneously several global classifications: those imposed by KO practitioners through epistemological and technical regulations; and those of the digital medium itself, reinforcing the former.

This occurs because the West, as a hegemonic "culture", is profoundly convinced that its categories of

2 Fully developed in García Gutiérrez (2005; 2007; 2008a; 2008b; 2011).

TransInformação, Campinas, 23(1):5-14, jan./abr., 2011 
local organization are necessarily of universal interest, without understanding the hostile, marginal or astonished attitudes to its proposals shown by other cultures and minorities. Such a"hetero-organizational"zeal appeared uniquely in the West with the advent of the Enlightenment (Horkheimer; Adorno, 2006), a cognitive and cultural matrix from which precisely an attempt was made to organize all "universal knowledge" in an Encyclopaedia (Olson; Nielsen, 2002), and which was increasingly more in keeping with a metonymic, dichotomic and neo-colonial interpretation of the world. The arguments set forth below will be limited to these constituent elements which, empirically speaking, are understood as classification.

\section{Metonymic reduction}

Metonymics is an epistemological tool that identifies the part with the whole. Daily or scientific classifications of Western organization of the world are expressions of a "metonymic" rationality which is part of the instrumental reason denounced by Weber or the Frankfurt School itself. Metonymic reduction is the reduction of reductions, a reduction whose only aim is to reduce, simplify, and fragment; a reduction overwhelmingly present in the processes of understanding, enunciation and classification favoured by the dominant form of contemporary rationality.

Cultures are built and maintained on the basis of immutable categories, prejudices and suppositions, and metonymics facilitates enormously the constitution and transmission of that world on offering it in partial visions and mutilating biases. Metonymics follows the progressive path of reduction of the world to the extent of converting it into a handful of slogans and clichés. It is for this reason that the metonymic language of marketing and advertising, which has already infiltrated the discourses produced in our culture, from the political to the purely scientific, is so efficient. To such an extent, in fact, that the exceptionality of the use of metonymics has become a commonplace cognitive tool, automatic and, therefore, scarcely detectable but overwhelmingly present in our daily discourses, choices and actions.

In his "Sociología de las ausencias" [Sociology of Absences], Boaventura Santos considers that metonymic reason is a form of rationality that imposes "a homogeneity on the whole and the parts, which do not exist beyond the relationship with the totality" (Santos, 2005, p.155). Accordingly, the totalities would have to be constructions forming a part of other totalities in a way that the world, seen from that point of view, would be no more than a giant house of cards ready to be knocked down by the smallest of movements or neglect of its fragile structure. For Santos, metonymic reason has two consequences. On the one hand, "it is held to be an exhaustive, exclusive and complete reason, although it is only one of the logics of rationality existing in the world. On the other, for metonymic reason none of the parts can be considered beyond its relationship with the whole [...]. So it is incomprehensible that some of the parts have their own life beyond the whole [...]. Western modernity, dominated by metonymic reason, not only has a limited understanding of the world but also of itself" (Santos, 2005, p.156).

The conviction, so firmly rooted in the West, of assigning a universal value to a strictly local and contemporary lifestyle has penetrated not only in the daily imaginary of westerners but also in pro-Western and fringe cultures, in many cases by means of the silent and gradual adoption of those same Western lifestyles, technologies and languages.

Two immediate cognitive actions are produced through metonymic reason:

1) The fragmentation and division of all the instances so as to be studied, dominated and exploited by parts like the human body, invaded cultures, or the Western agencies themselves at the service of an essentialist supra-Western efficiency, as occurs in the field of science, politics, values or the division of labour.

2) The promotion of an arbitrary and irresponsible logic that, far beyond from Morin's hologrammatical principle (1996), involves identifying the division with the whole of which it was just a part. Thus, classes and parts are regarded in an uncontrolled process as species and wholes, and that such a logic begins to operate in daily practices as an unstoppable epistemological flow. In the forest of knowledge, each tree, trunk and branch would occupy an unquestionable place.

I am well aware of the abuse of using yet again a botanic metaphor, which has enjoyed much popularity in the realm of science and in the dissemination of 
metonymic thought, since it was advanced by Porfirio. But precisely for being one of the metaphors that has provided knowledge with the greatest number of reductions, I do not want to avoid it. The harm is not to be found in the metaphor but in the perverse use of the phoroi beyond semantics. In fact, Deleuze and Guattari (1994) retrieved and rehabilitated the botanic metaphor by means of the rhizome, a set of anarchical, discontinuous, capricious and tangled roots, like those of the Southern mangroves, as a figure of epistemological dismantling. That is the nutrient from which sprouts the theory of declassification put forward in this article.

\section{Dichotomic reduction}

Once it has obtained the licence of metonymic production, classifying thought arms itself with two sharp properties:

- Sliding: this involves a kind of uncontrollable movement that allows us to pass unjustifiably from one instance to another for the mere fact of possessing homonymous, homographic and homophonic representations. Lacan underlined the effect of metonymic sliding across the structure of signifiers themselves. The discursive situation is undoubtedly responsible for the sliding that occurs in one direction or another. But, despite being generated on the surface of meaning, the effects on this (for understanding or for enunciation) could not be more decisive.

- Dichotomization: dichotomy offers a world constructed by means of opposing pairs. All instances are constructed on an opposite. Dichotomy also transfers an order of priority in the binomial, since the position is not neutral. In fact, the instance occupying the first position in a dichotomy tends to be favoured by the social, economic or cultural order: North vs. South, white vs. black, man vs. woman, boss vs. worker, rich vs. poor, centre vs. periphery. Hence, Santos himself proposed "a procedure rejected by metonymic reason: to consider the terms of dichotomies outside the articulations and relationships of power that unite them, as a first step towards freeing them from the said relationships and revealing other alternative ones that have been obscured by the hegemonic dichotomies. To consider the South as if the North did not exist, to consider women as if men did not exist, to consider the slave as if the slave owner did not exist" (Santos, 2005, p.160). For Santos, metonymic reason does not know how to absorb the multiple elements that remain wandering about outside dichotomies, and which have to recover or gain their own voice: "What exists in the South that escapes the dichotomy North/South? What exists in traditional medicine that escapes the dichotomy traditional medicine/modern medicine? What exists in women that is independent of their relationship with men? Is it possible to see what is subordinate without taking into account subordination?" (Santos, 2005, p.160).

After dichotomies comes a crushing logical order that I think that, to differ from the opinion of Santos, is not exclusive, even less so of Western culture, but rather a constant in any culture or personality that seeks domination and expansion. But in our culture, dichotomy is to reason what the atom is to matter. And such an order impregnated morals: good/bad; law: innocent/ guilty; politics: in favour/against; digital technology: 1/0.

In my book Desclasificados [Declassified] (2007), from the demolition of dichotomies, I developed a provoked construction of oxymora and hyperbatic oxymora (inversions), inducing the cooperation of the elements of many automatic oppositions, such as centre/periphery, so as to transform them into two efficient epistemological and heuristic resources: central periphery (Bangalore or São Paulo, for instance) and peripheral centre (be it The Bronx or the poorest districts of LA). The calculated construction of oxymora and contradictions is a powerful metacognitive tool of declassifying thought.

\section{Analogical reduction}

As Umberto Eco stated in Kant and the Platypus (1999), which, in my opinion, is his best work on knowledge theory, with repercussions that cannot be ignored by experts in classification, British zoologists spent the best part of the $19^{\text {th }}$ century debating on how to classify the platypus, a likeable animal discovered for Western biology by colonists in Australia and New Zealand. The aborigines had already made this discovery thousands of years before and had never argued about its zoological classification. The platypus has a duck's beak and lays eggs (bird), a furry tail and strange mammary glands (mammal), it slithers and has claws (reptile), in addition to spending half of its 
life in aquatic environments where it hunts and obtains sustenance (amphibian). After much debate, the mastozoologists arrived at the conclusion that the animal should be regarded as a mammal. It is important to note that being a mammal meant that it occupied a rather privileged position in the animal order. They had to make a choice and decided on that taxonomy, although how could they explain, among other things, the matter of the eggs and beak?

Several zoologists, according to Eco, made extravagant comments as regards the platypus, for instance regarding its position in the animal order: mammals with parts of other animals or an exceptional mutation. Recent discoveries show that the platypus belongs to a species that, for millions of years, has been regressing towards its involution. Therefore, should it still exist within a few millions years, might it possibly have abandoned the realm of mammals entering that of a different taxonomy, a taxonomy that could have existed before mammals?

Comparing formal Kantian categories with the Peircian concept of thirdness, Eco expounds upon the cultural imperative, how taxonomies are reproduced through mechanisms of recognition, taking the famous example of Marco Polo when, on seeing an Asian rhinoceros for the first time during his journey to the East, classified it as a unicorn because of its resemblance to a known animal that, for another thing, never existed except in mythological narrative and paintings that Polo himself had had the chance to familiarize himself with in Venice.

Several civilizations and cultures - for instance, subcultures that are not necessarily territorial, such as the scientific one - have specialized in "heteroclassification", in drawing up lists of clichés with which the classified subjects and objects have to comply, knowing full well that the inclusion of all the subjects and objects in the same category is usually forced, or that the category ends up by exploding due to internal pressure or because of the dynamics themselves of the restless world that it intends to subordinate. Epistemological and scientific categories are not prepared to assume constant change from a totalist supra-ordering.

To catalogue, classify, separate, and divide: here are some of the keywords of our classifying culture. In view of the panorama presented by classification, we should ask ourselves what influences are behind such an unbridled classification, what are the advantages of classifying the world in this way and, above all, what can an alternative theory do in this respect? Psychological theory of cognitive dissonance can probably provide a satisfactory answer to the first question. The second would involve a sociological, political and ethical debate which I have no intention of avoiding in this paper, but rather of using as a foundation stone; and the third requires a theoretical answer that, from a critical and post-colonial approach, I will address in the following section.

\section{A new position of enunciation}

The position from which we consider the world has a lot to do with Epistemology: it is our epistemological position. From where do we usually consider classification epistemologically? In my opinion we do this from an apparently neutral and non-ideological position, where conflicts are of an exclusively techno-scientific nature, despite the fact that we operate and produce ideology and culture.

Further on, I will propose the construction of a position of post-epistemological enunciation unconditionally presided over by hermeneutics (Capurro, 2000). Hermeneutics is the democracy of thought. Conventional Epistemology excludes hermeneutics, but hermeneutics integrates Epistemology as just another interpretation. My inflexible request is, as a result, the substitution of the spirit, language and procedures of the Epistemology of classification by a hermeneutics of $\mathrm{KO}$ that we will call "declassification". A revision that involves addressing complex processes of translation, the suspension of certain assumptions or the mere formal transformation of others that adapt to the liberalization of a wider and inclusive cognitive matrix. From there, and in honour of hermeneutics itself, there might stem adjectivations, nuances and options.

Therefore, reconsidering our study field would involve being open to post-colonial positions, to those of different sensibilities and contributions, such as those of Walter Mignolo (Mignolo, 2003; Mignolo; Schiwy, 2007) and Bhabha (1994), or Santos (1989; 2005) along the same lines, when they propose a southern thought, as a metaphor of that immense space of diversity, although a south not understood simply as a geographical place 
but as a place of suffering, discrimination and exploitation on a planetary scale, including the supposedly "developed" territories of the northern hemisphere. "Paradigm-other" and "thought-other", as this way-other of considering the world is usually called by the aforementioned theoreticians. Identity-other, memory-other (García Gutiérrez 2008a; 2009) would be their correlates. Hermeneutics without epistemological frontiers, without the urge for hierarchization, exclusion, fragmentation, disjunction; even the complexity of Edgar Morin would be highly compatible with such a post-colonial way of thinking.

We have a reasonable objection to postcolonial theory: in several of his works, although above all in Empire (Hardt; Negri, 2002), Toni Negri objects to the fact that the emancipating project furthered by modernity is forgotten in part on becoming bogged down by the discussion revolving around the old colonial categories of which it has never quite managed to rid itself. Taking into account Negri's objection, I advocate for a position of enunciation whose chief aim is permanent decolonization, since, in my view, domination is intrinsic to human nature and, with each new subject and generation, it would be necessary to reopen the case for decolonization.

Scientific information, which at first dealt with the management and organization of the sciences, even by means of reckless universal classifications, also ended up by organizing social, cultural, media, artistic and aesthetic knowledge. Through the management and organization of archaeological, historic and anthropologic documents, scientific information ended up by invading and modifying our vision of many contemporary cultures and identities in dissolution and the image that they have of themselves.

Through other hyper-classifying disciplines, such as archival science and museography, non-scientific documents and objects belonging to contemporary cultures or those of past eras are addressed, although these are far-removed from the interests of their classifiers and curators. This fundamental detail, to classify the immensity of the "otherness", should be sufficient to incorporate in our studies new visions and logics, a greater pluralism and sensibility for considering new objects that ought to be protected and classified or, better still, declassified so as to allow them to protect themselves.
What would be involved, therefore, is not only the optimization of our processes of information on an immense amount of knowledge subordinated or excluded by hegemonic knowledge, but especially the reinforcement of genuine forms of information and self-narrative of those sectors and the incorporation of their worldviews and logics in the microphysics of digitality.

\section{Declassification in KO}

Declassification basically involves introducing pluralism in the core logic of classification. It is a metacognitive and non-automatic operation that, in each action of the classifier, requires a complete awareness of incompleteness, bias, and explicitable subjectivity. With current technology, it is possible to elaborate procedures and systems of classification based on declassification. But such techniques and tools will also have to undergo an epistemological revolution in all their protocols and strata.

If, so as to think in a declassifying fashion, we need a fixed position from which to observe fixed objects, we would be classifying according to the conventional order of classification, paralyzing the world from a sclerotic perspective. Declassification is a dynamic form of organization that, primarily, should satisfy a rationale of change: that of the organisable symbolic objects themselves, once the reduction of the traditional cognitive paralysis of the type of classification we normally practise has been overcome.

The logic of change (Hegel, 2000) underlying declassification must be understood in at least two universes, sometimes opposed and sometimes collaborative: firstly, we would conceive a change of a spontaneous and arbitrary nature, but nevertheless a change that, in some way, could be regarded as determinist, not for driving the world inexorably towards its destiny, but for finding the inexorable destiny of the world in the change itself. We conceive this kind of change as a movement or spontaneous impulse.

Secondly, we would have to understand the change from the perspective of the universe of will, a transformative universe. The change would therefore be governed by an articulated double path on movements and transformations. Movements generating new 
movements that interact, replace, and displace the meaning of some transformations that, to a minimum extent, but with the only authority that we know, the authority that the meaning confers on us, produce deviations and drifts in the movements.

Classification would emerge as a spontaneous movement within the initial cognitive matrix, equipped from the start with a will of power, which orientates perceptions and pretentions of all possible meanings in the sole direction of the perceptions and pretentions of the will of power. In fact, in spite of the atomization of power that springs from the Foucauldian conception (Foucault, 1979), power maintains its totality in a microcosm of daily manifestations. And one of its resources and manifestations is classification, a powerful and millennial classification protected by tradition, wisdom, knowledge, memory, identity, stability, religion, culture, science and our way of life, as is customarily said, all cooperating in pursuit of an identical and immutable classification that unceasingly divulges its structures. A classification conceived as the world's origin and destiny, always submissive and reinforcing the established order in spaces in which perhaps no order is necessary.

In cultural practices, in which language and languages provide a basic dimension, essence, "is-ness", that is, ontological purification stemming from the verb to be, becomes a reference and priority resource for perceiving and transmitting the symbolic world. In a diversity of manifestations, the concept "to be" exists in all known languages and cultures, allowing thinkers to talk about the attributes and properties of an object, of themselves or of a community, in the same way as rejecting them.

Partitive or classematic conceptual relationships, distorted by metonymics, act as an automatic resource that clarifies a proposition, while at the same time dulling the rest. The hierarchies of the whole over the parts, and of species over classes, organize the world. That same logic of hierarchization, whether it is prior or subsequent to the microstructures of power, organizes the relationships between subjects and objects, between objects and objects, and between subjects and subjects.

When we allude, with automatism or innocence, to the parts of a house, a car, an institution, a city, a computer, or to the classes of any kind of object or subject, we are classifying the world in an essentialist fashion.
Explicitly or tacitly, the verb "to be" connects the part with its whole, the class with its species: the wheel (is) part of the car; the screen (is) part of the computer; the kitchen (is) part of the house; the house is a dwelling; sardines are fish; and the computer is technology. Essentialist operations consist in organizing the world from a unicist and reductive logic. We call that rudimentary logic "classification" and it already impregnates the nuclear ordo of natural language itself.

Declassification does not deny classification, because we never stop classifying, but involves the metacognitive assumption of a different, plural and nonessentialist logic. Declassification introduces logical pluralism, possible worlds, doubt and contradiction in propositions, justly providing an anti-dogmatic thought, a weak thought, one might say, invoking Vattimo (pensiero debole).

Simple formulae, defying the principle of noncontradiction, as "a thing is also always another thing", introduce falibilism, perspectivism, logical pluralism in thought and classifying argumentation. What is more, the factual affirmation (is) would be even more mitigated by the counterfactual enunciation: "a thing could always be another thing".

What decides a super-ordering or subordination is the situation, an enveloping and absorbing position blocking other alternatives and impeding the alternative of insubordination or conceptual non-subordination. It is possible to infer that, beyond the situation, relationships are submitted to infinite possible and arbitrary worlds as a criterion of ordering. If as an example we take other functionalities of the instances alluded to in other situations (of real possible worlds), in the modal logic of Lewis (1986) the knife could be a murder weapon, a keepsake or an antique; the dog could be a bothersome barker or a loyal companion; the holm oak could provide shade or also be an unknown tree; the computer could also be polluting waste; the sardine could be healthy or not.

Something out of context is always and simultaneously multiple things. Infinite conceptions lie in wait for instances, shaping and reshaping propositions. And to confirm several propositions simultaneously is not contradictory; it is simply a declaration of uncertainty. Therefore, an instance is not only, it is also. By means of 
the explanation "it is also", let us see how declassification surprisingly interrupts conceptual hierarchies, cancelling the privilege of any classifying vision: the knife is also a piece of cutlery; the dog is also a mammal; the holm oak is also a tree. Those instances "they are also", that is to say, the supra-ordering criterion established by custom, discourse or culture, become dishonoured, degraded, by infinite pragmatic worlds ready to take their place.

To state that any instance is also, implies dismissing tradition or imposition from whose perspective the concept has been seen and considered, as well as its supra-ordering and subordinate elements, and transferring declassifying pluralism to the core itself of conceptual refounding which democratic thought requires.

To state simultaneously several propositions is not contradictory, since it is rather a declaration of uncertainty. There is no criticism of its contradictory nature. We can also state several opposing propositions and, however, we would still be saying something. We would always be saying something and, if we calculate the contradiction, we would certainly be saying something tremendously different and creative. Declassification would be a way of guaranteeing equal opportunities for the diversity of knowledge, logics and conversations in a digitality-other.

\section{Declassifying operators in classification systems ${ }^{3}$}

In this section, which is more applied to and focused on sectors working with events and stories in the media, political, social and cultural worlds, genres that move from and between journalism and history, I am going to describe two types of operators that, hypothetically, would help to break with unilateral and homogenizing schemas of dependence, whose presence is massive and disturbing. In any case, what is involved is a theoretical proposal of operators that, in a declassifying fashion, organize worlds spanned by constructions of history and memory, many fields of humanities and sciences or media discourses. Such theoretical operators would have to be incorporated either by forcing or replacing and eliminating the hierarchical or reductive functions of the traditional operators of classifications, thesauri and ontologies.
What is understood here as an operator is a logical-semantic tool (and, it should not be forgotten, of a necessarily ethical and political nature), whose primordial function involves establishing relationships betweens registers and serving as a link between these and the participants in a network. For instance, the hierarchical tools BT, NT and associative RT, belonging to conventional thesauri, are operators of organization that satisfy precise, unequivocal and symmetric epistemological criteria.

The basic difference of this type of closed and univalent operators, with respect to my proposal, lies in the logics on which they are based. Declassifying operators are precisely resources of intervention and facilitation whose aim is to guarantee decolonizing thought and the equal flow of information systems, but also to warn citizens about those registers that contravene interculturally established decisions and agreements, such as human rights, to question certain presences by means of the legitimate criticism of producers-mediators and usersmediators, and to promote a social transformation keyed to emancipation and plurality of knowledge.

On being open, the logic of the operators proposed here includes the closed logic of the traditional relational operators BT, NT, and RT, or any other one, and as a result it does not oppose them provided that they contain the principles of declassification. So, for example, under declassification we could continue to use operators of classive and partitive hierarchies, whole/part and genre/ specie, subject to the extirpation of their logic of subordination and supra-ordering as a primary systemic logic, operating as mere partial resources of proximity, provided that they do not stem from the reproduction of epistemological, social or hegemonic political hierarchies.

In accordance with the postulates established by the theoretical considerations put forward in the previous sections, the declassification of $\mathrm{KO}$ systems in the aforementioned sectors could have an anti-dogmatic, hermeneutic and decolonizing operator, that is, based on the imperative of the direct democratic participation of all the possible positions and worlds that need it including all the oppositions and contradictions regarding a conception - built in a plural fashion so as to ensure the presence of all the worldviews and propitiate the differences even of those positions regarded as unjust

\footnotetext{
3 The complex operator is fully describes in García Gutiérrez (2008a). As to the transcultural operator, see García Gutiérrez (2011).
} 
or anti-democratic. Under the priority of ideological and logical pluralism, but also facilitating part of that established in the principles of interaction and transformation that orientate the promotion of social change, I propose complex operator $\Lambda$. Such an operator would be essential, for instance, in conceptual maps in which appear complex notions like terrorism, veil, "illegal" people or abortion, to mention only some of the most controversial ones. Operator $\Lambda$ would guarantee all the ideological interpretations and equal opportunities of those concepts. The complex operator is not designed to intervene in or control visions and meanings as regards an issue.

Furthermore, an anti-relativist and critical operator would act in a compensatory fashion, that is, it would side against injustices and inequalities established in the exomemory, intervene in the conflicts of interest between local positions and inter-ideological agreements, establish conditions for dialogue keyed to consensus, and apply the results of the latter. Transcultural operator $\vee$ would be responsible for those functions.

Let us look at several clarifying issues touching on the shared and different aspects in both operators, operators that do not oppose each other, but intersect, supervise and complement each other. Complex operator $\Lambda$, whose most notable function would be to detect confrontations, contradictions, oppositions, dichotomies and antonymies in pursuit of their coexistence, includes all the possible meanings of an issue or the meaning of unshared issues, specifying them so that all participations or searches in the network are recognized by the shared subjectivities of a community or culture or by individual subjectivities. It is therefore an operator closer to de facto multiculturalism, to an initial co-presence of positions in equal conditions and with the same chance of visibility.

With regard to transcultural operator $V$, it is the synthetic product of a permanently open, democratic dialogue between representations of diverse positions (political, cultural, discursive, etc.) that negotiate the homologation and integration of certain issues that affect them from argument premises (and not mere arguments) or topoi. Therefore, this operator $V$ implies the reaching of an agreement with respect to an issue and its formalization as a category transversal to the positions as a transcategory, constituting, from such a sanction, an ethical world norm that could interfere in the local registers that infringe it, not invalidating or censoring them, since they would always enjoy the protection offered by the complex operator, but warning the participating citizens about their content. García Gutiérrez (2002b; 2008a; 2008b; 2011) sets out the basics of the dialogue that should govern the plural construction of intercultural agreements in the field of KO, based on the discursive ethics of Apel (1985).

Both operators are profoundly democratic, since when $\Lambda$ is supported by the specification of all the positions and worldviews, without exclusion, as itineraries of representation and localization of the registers, that is, guaranteeing the representativeness on an equal footing of all the initial positions with respect to an issue, $V$ is essentially regulative and executive, that is, it balances the possible unjust treatment of some or other position in the network, even respecting the presence of such registers accommodating the prior principle of emancipation, in terms of a transculturally accepted categorical scale in such a way that abuses in the network do not go unpunished if the transcultural community can avoid it with alerts, warnings and recriminations. As a result, the transcultural operator is as fully democratic as the complex operator, since its application would only be authorized by democratic decision (transcultural synthesis) endorsed by the majority of the positions, a consensus that can be widened and must be revised periodically.

While the transcultural operator is the antidote to the relativism of which the complex operator could be accused, which does not determine the moral or cultural merits of a register, concept or position, the complex operator likewise involves the democratic and hermeneutic balance of a transcultural operator accused of a lack of support or sufficient legitimization. If the complex operator leads all the positions and perspectives to mutual friction from which emerge third itineraries, spontaneous and deliberate new connivances, the transcultural operator is substance of a dialogical rationality in pursuit of convergence.

The complex operators are linked at a systemic level, that is, to an "epistemography" as a concept network or open system (García Gutiérrez, 2002a; 2002b; 2007; 2008a; 2008b). The complete visibility of the democratic function of this operator only appears at the system level, and not in each particular register. Traditionally, $\mathrm{KO}$ has centred one of its main lines of research and development on the construction of languages and systems that, from homogenizing or highly biased perspectives, commonly 
represent discursive content and forms independently of cultural variables and the full conglomerate of sensibilities and singularities that operates both in the conformation of those complex, simplistically represented worlds, and in the access, appropriation and continuity of those representations. Therefore, operator would disrupt the logic and appearance of conventional classification systems and languages.

\section{References}

APEL, O. La transformación de la filosofía. Madrid:Taurus, 1985. BHABHA, H.K. The location of culture. New York: Routledge, 1994.

CAPURRO, R. Hermeneutics and the phenomenon of information. In: Mitcham, C. (Ed.). Metaphysics, epistemology and technology: research in philosophy and technology. New York: Elsevier, 2000. v.19, p.79-85.

COSTA, N.C.A. O conhecimento cientifico. São Paulo: Discurso, 1997.

DELEUZE, G.; GUATTARI, F. Mil mesetas: capitalismo y esquizofrenia. Valencia: Pretextos, 1994.

ECO, H. Kant y el ornitorrinco. Barcelona: Lumen, 1999.

ELSTER, J. Ulises y las sirenas: estudios sobre racionalidad e irracionalidad. México: FCE, 1989.

FOUCAULT, M. Microfísica del poder. Madrid: Las Ediciones de la Piqueta, 1979.

GARCÍA GUTIÉRREZ, A. La memoria subrogada: mediación, cultura y conciencia en la red digital. Granada: Editorial Universidad de Granada, 2002a.

GARCÍA GUTIÉRREZ, A. Knowledge Organization from a "Culture of the Border": towards a transcultural ethics of mediation. In: López Huertas, M.J. (Ed.). Proceedings of the Seventh International Isko Conference: advances in knowledge organization. Würzburg: Ergon Verlag, 2002b. v.8, p.516-522.

GARCÍA GUTIÉRREZ, A. Fijaciones: estudios sobre tecnologías, culturas y políticas de la memoria. Madrid: Biblioteca Nueva, 2005.

GARCÍA GUTIÉRREZ, A. Desclasificados: pluralismo lógico y violencia de la clasificación. Barcelona: Anthropos, 2007.

GARCÍA GUTIÉRREZ, A. Dialéctica de la exomemoria. In: Valle, C., et al. (Ed.). Contrapuntos y entrelíneas sobre cultura, comunicación y discurso. Temuco, Valparaíso: Universidad de la Frontera, 2008a. p.232-260.

GARCÍA GUTIÉRREZ, A. Outra memória é possível: estratégias descolonizadoras do arquivo mundial. Petrópolis: Vozes, 2008b.

GARCÍA GUTIÉRREZ, A. Laidentidad excesiva. Madrid: Biblioteca Nueva, 2009.
As to transcultural operator $V$, even performing at the systemic level as well, its complete realization is only achieved when it is specifically assigned to a register affecting the provided analytic description by means of other resources used by the position and local interest. However, its efficiency lies in a constant activism by intercultural dialogues and the adequate use to which it is put by culturally and socially committed mediators.

GARCÍA GUTIÉRREZ, A. Epistemología de la documentación. Barcelona: Stonberg, 2011.

HARDT, M.; NEGRI, A. Imperio. Barcelona: Paidós, 2002.

HEGEL, G.W.F. Fenomenología del espíritu. 7. reimp. Madrid: Fondo de Cultura Económica, 2000.

HORKHEIMER, M.; ADORNO, T. Dialéctica de la ilustración. Madrid: Trotta, 2006.

LEWIS, D. On the plurality of worlds. Oxford: Blackwell, 1986.

MIGNOLO, W. Historias locales, diseños globales: colonialidad, conocimiento subalterno y pensamiento fronterizo. Madrid: Akal, 2003.

MIGNOLO, W; SCHIWY, F. Transculturation and the colonial difference: double translation. Información y Comunicación, n.4, p.6-28, 2007.

MORIN, E. Introducción al pensamiento complejo. Barcelona: Gedisa, 1996.

OLSON, H. Transgressive deconstructions feminist/ postcolonial methodology for research in knowledge organisation. In: Frías, J.A.; Travieso, C. (Ed.). Tendencias en organización del conocimiento/trends in knowledgeorganisation research. Salamanca: Universidad de Salamanca, 2003. p.731-740.

OLSON, H.; NIELSEN, J.; Dippie, S. Enciclopaedist rivalry, classificatory commonality, Illusory Universality. In: López Huertas, M.J. (Ed.). Proceedings of the Seventh International Isko Conference: advances in knowledge organization. Würzburg, Germany: Ergon Verlag, 2002. v.8, p.457-464.

PEÑA, L. Algunas aplicaciones filosóficas de lógicas multivalentes. Theoria, n.16-18, p.141-163, 1992. Disponible en: <http://www.sorites.org/lp/articles/logica/aplicaci.htm>.

RORTY, R. La filosofía yel espejo de la naturaleza. Madrid: Cátedra, 1983.

SANTOS, B.S. Introdução a uma ciencia pósmoderna. Rio de Janeiro: Graal, 1989.

SANTOS, B.S. El milenio huérfano. Madrid: Trotta, 2005.

SODRÉ, M. As estratégias sensíveis: afeto, política e mídia. Petrópolis: Vozes, 2006. 